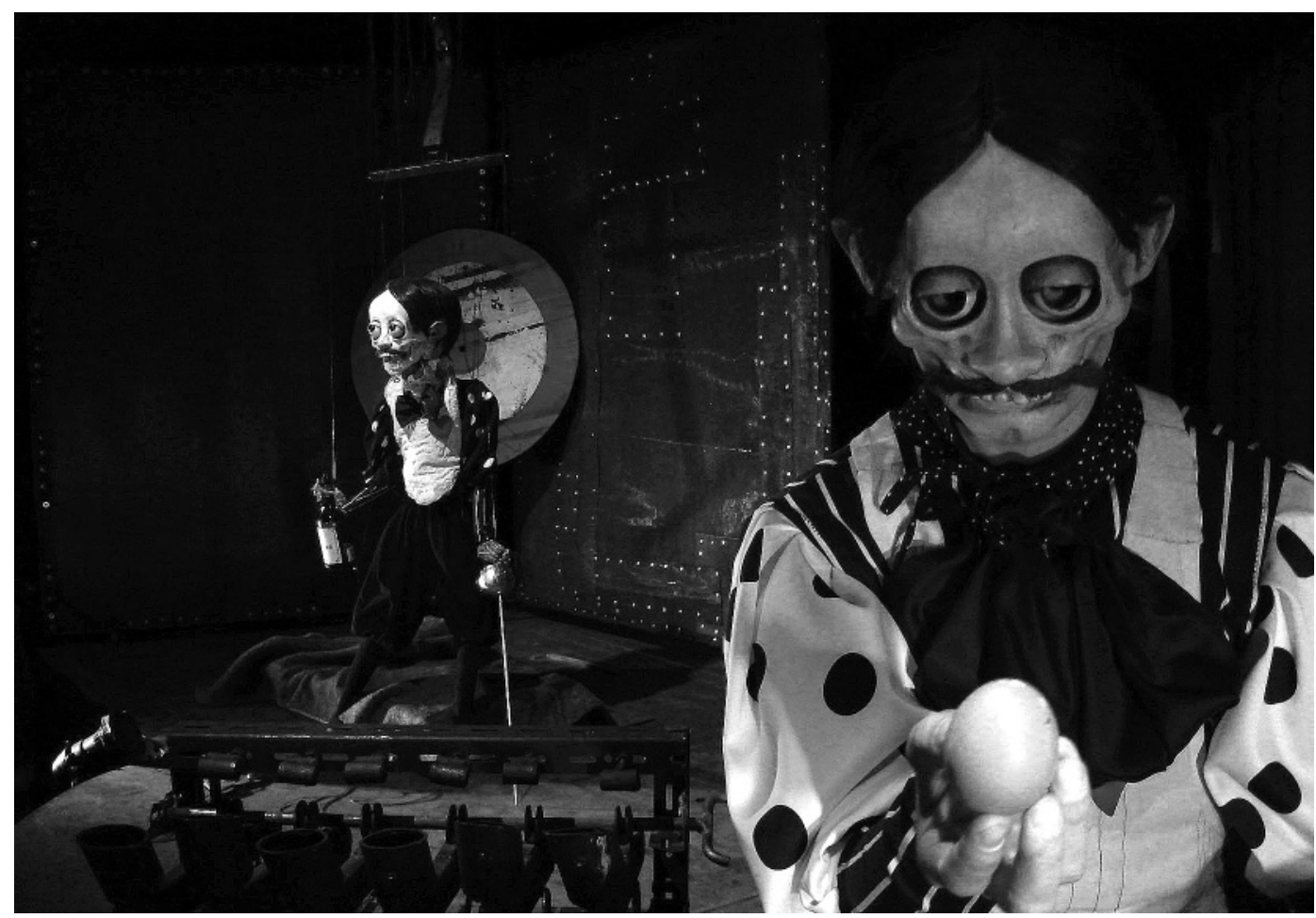

\title{
A "expressão privilegiada do teatro" o FIMFA e João Paulo Seara Cardoso
}

\section{João Carneiro}

\section{Gostaria de começar com uma citação:}

\begin{abstract}
No inicio, quando as portas do teatro se abriam, viam-se doze personagens, organizadas em três grupos. Representavam outros tantos gregos, que trabalhavam a construir navios, junto da margem onde os deveriam lançar ao mar. Essas personagens mexiam-se, umas a serrar, outras a partir madeira, outras a martelar, outras ainda a fazer furos ou escavar. Faziam muito barulho, tal como os operários verdadeiros. Ao fim de algum tempo a cena fechava-se, e depois abria-se de novo, oferecendo uma vista diferente. Assistia-se agora ao lançamento dos navios ao mar, ao que se seguia uma outra cena que só mostrava o céu e a água. Logo a seguir começava o desfile dos navios, organizados como uma frota. Uns desapareciam, outros apareciam várias vezes. Dos lados andavam golfinhos, uns mergulhando outros emergindo das áquas, como verdadeiros peixes. Pouco depois o mar encapelava-se, e os navios seguiam numa fila serrada. Nem uma vela no horizonte, mas sim Nauplius, agitando a sua tocha, e em pé, junto dele, Minerva. Então, uma chama, visivelmente alimentada pela tocha, iluminava o horizonte. Naufrágio dos navios, aparição de Ajax a nado. Provocado por um mecanismo escondido debaixo do teatro, rebentava o som de um trovão, e Ajax era apanhado por um raio, desaparecendo subitamente. Então a cena fechava-se uma última vez, marcando o fim da representação (Plassard 1996: trad. minha).
\end{abstract}

Trata-se da descrição de um teatro mecânico, feita por Heron de Alexandria, um século depois de Cristo, há quase dois mil anos, portanto. A referência deverá ser a guerra de Tróia, mas isso não é o mais importante. É uma representação do mundo feita através de figuras que representam pessoas, através daquilo a que se podem chamar também bonecos. Há também representações de peixes, e representações de uma paisagem - a água, o céu, até mesmo os relâmpagos e o fogo.

A descrição é uma das muitas que poderiam ser dadas como exemplo de uma maneira de representar dramaticamente o mundo dos homens, dos animais e das coisas através de processos que nos levam de imediato para aquilo a que chamamos marionetas, bonecos que representam pessoas e animais. Não são diferentes dos bonecos e dos animais que constituem os brinquedos das crianças, mas as suas funções, se orientadas também para o universo infantil, representando personagens, cenas e histórias que prendem a atenção de pessoas ainda pequenas, rapidamente extravasam do universo infantil para o universo das pessoas, pura e simplesmente, pessoas de todas as idades.

Existem descrições deste tipo de representações, organizadas desta maneira, que é a maneira como se organiza o teatro, muito mais antigas, e muito mais variadas nas suas proveniências geográficas; a bem dizer, elas existem em praticamente todo o mundo conhecido. Por vezes elas apontam para realidades tão etéreas, imateriais, delicadas e sofisticadas que são feitas só com sombras, ou com luz, o que vem a ser o mesmo. Por vezes as figuras estão dentro de água, por vezes a maneira de as fazer 


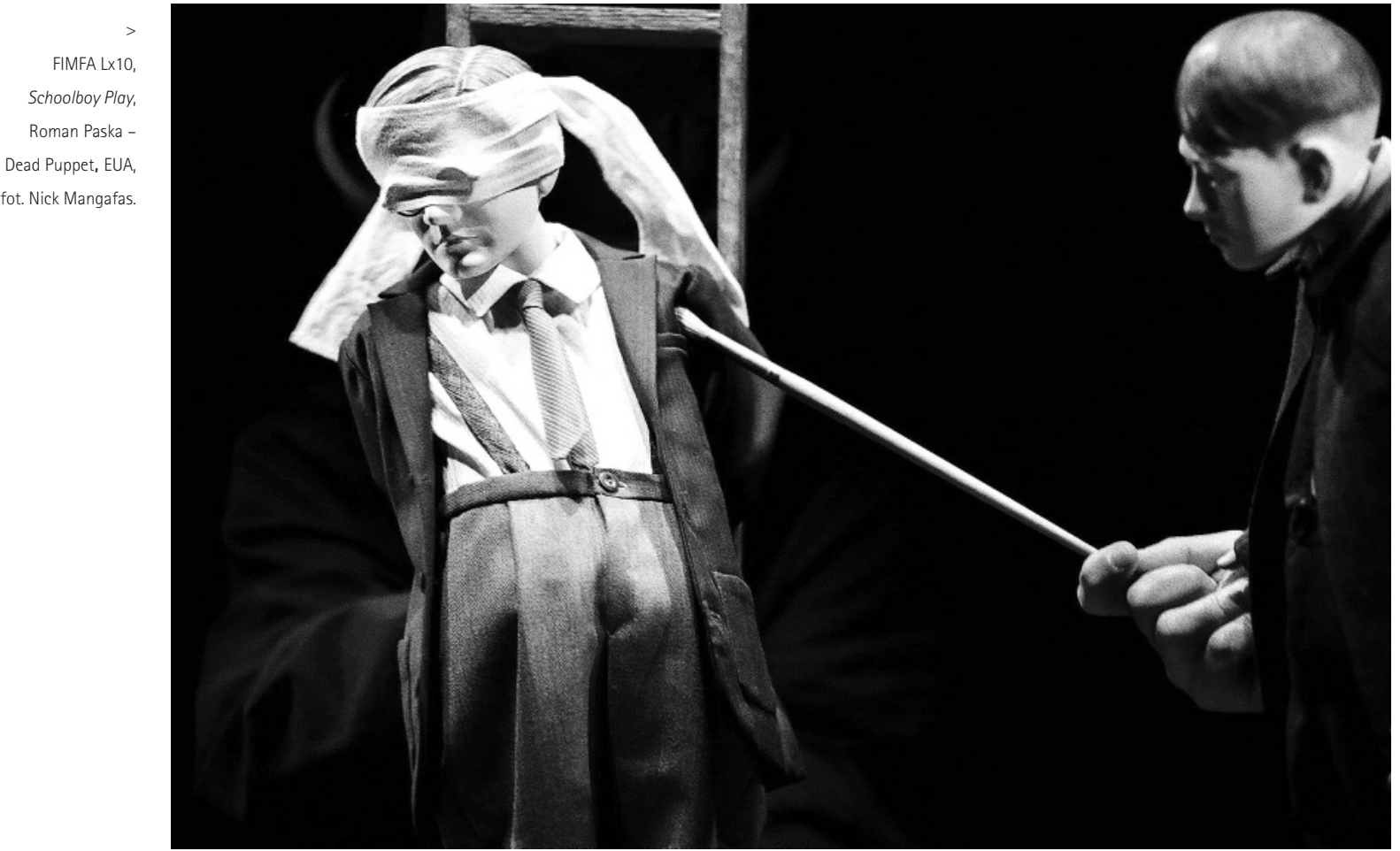

mexer é com fios, ou com varas, por vezes quem manipula pega directamente naquilo que manipula e que mostra.

0 universo das marionetas não tem limites nas variedades que a criatividade artística permite.

É esta variedade de representações e de registos de representação que o FIMFA Lx, tem vindo a mostrar de maneira exemplar, todos os anos desde 2001. Festival Internacional de Marionetas e Formas Animadas, o FIMFA partiu da vontade de Rute Ribeiro e Luís Vieira, os dois marionetistas que começaram por fundar a sua própria companhia, A Tarumba, que continua a sua actividade enquanto tal. Mas o Festival que eles criaram tem trazido a Lisboa, e cada vez mais para além de Lisboa, uma substancial parte daquilo que constitui o universo das marionetas, em geral. Da Rússia, da República Checa, da Índia, do Japão, de Taiwan, da China, de quase toda a Europa, da América, os lugares são cada vez mais, e o espaço mais abrangente. As tradições quase perdidas do teatro oriental, o património de artistas itinerantes que já pouca gente conheceria se não fossem pessoas como o Luis e a Rute a mostrá-los, os desenvolvimentos recentes destas formas de espectáculo, tudo tem passado pelo FIMFA, e invadido a cidade. O TNDM II, o Teatro São Luiz, o Teatro Maria Matos, o Teatro Taborda, o Teatro Aberto, o Chiado, o Largo do Camões, os jardins do CCB, o Convento das Bernardas, os passeios em frente do Convento das Bernardas, nada tem escapado à invasão destes bonecos e destas formas animadas. Bonecos de Santo Aleixo, Teatro de Marionetas do Porto, 0 Bando, Criadores de Imagens, Teatro de Ferro, Madalena Vitorino, Mestre Filipe e as Suas Marionetas, Lua Cheia - a presença portuguesa tem sido uma preocupação do Festival. E das formas japonesas à tecnologia finlandesa do WHS, das carroças centro europeias dos Viti Marcika às misteriosas figuras de Stephen Mottram da truculência russa do Akhe Theatre aos efeitos de Laterna Magica de Hermann Bollaert, nada tem escapado a um festival que permite, ainda, que o contacto entre o público e os artistas, entre artistas e artistas, entre aprendizes e professores, entre principiantes e profissionais

experimentados seja, cada vez mais, um dado crucial para a integração das marionetas e formas animadas na vida das pessoas.

Neste contexto, falar do João Paulo Seara Cardoso é como falar de tudo isto a partir de uma só pessoa.

Devo-lhe a minha descoberta do universo das Marionetas e das Formas Animadas, como expressão privilegiada de teatro, e essa descoberta deve-se a dois espectáculos muito diferentes entre si: Miséria, de 1991, e Vai no Batalha, de 1993. 0 primeiro era uma meditação poética sobre a vida e a morte, reunindo técnicas de tradição popular e uma reavaliação dessas mesmas técnicas, sob a forma de uma narrativa cénica invulgarmente sofisticada. 0 segundo, que vi nas instalações do irresistivelmente pequeno e acolhedor Teatro de Belomonte, era uma revista à portuguesa para marionetas, que numa escala reduzida, numa intensidade máxima e com um efeito retumbante, conseguia recriar quer a euforia do espectáculo musical, quer a graça própria das sátiras revisteiras.

O João Paulo Seara Cardoso, que nasceu em 1956 e morreu em 2010, tinha começado muito antes, quando depois da sua formação se dedicou à pesquisa do teatro popular de fantoches, o Teatro Dom Roberto, que mestre António Dias, em reconhecimento da sua dedicação e competência, acabou por the legar, em 1980. Depois de muitas representações do Teatro Dom Roberto, João Paulo Seara Cardoso cria, em 1988, o Teatro de Marionetas do Porto. Com essa companhia, que perdura saudavelmente com a direcção de Isabel Barros, criou espectáculos que marcaram a criação contemporânea do teatro de marionetas em Portugal, e do teatro em geral - Exit, Nada ou o silêncio de Beckett, Óscar, Macbeth, Paisagem azul com automóveis, Cabaret Molotov - para citar só alguns. Criou quatro séries de programas para a televisão, dedicados à infância, A árvore dos patafúrdios, Os amigos do Gaspar, Mópi e 


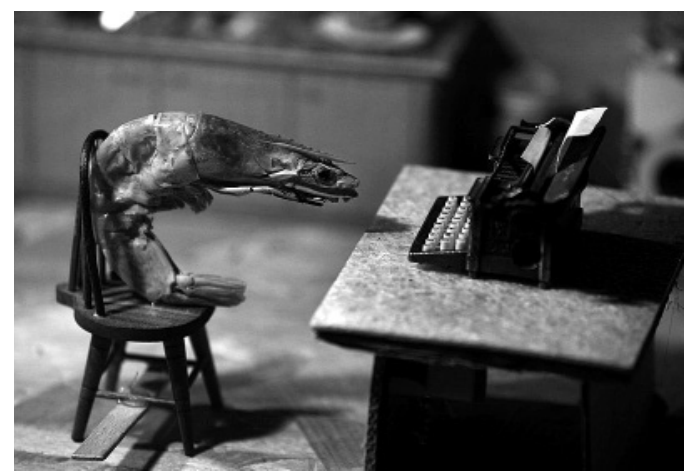

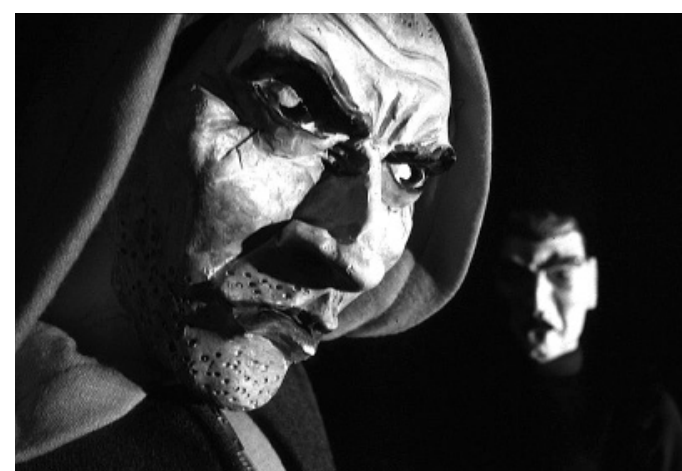

No tempo dos Afonsinhos. Encenou peças de teatro para outras companhias, encenou ópera, escreveu livros para crianças, geralmente como textos de base para outros tantos espectáculos.

Ao longo de toda esta incrivel carreira criativa, foi desenhando uma estética com características importantes, de que gostaria de salientar duas.

Por um lado, se o teatro de marionetas começa - e utilizar o termo "começa" é abusivo, uma vez que o teatro de marionetas apresenta-se, no seu polimorfismo, tudo menos um universo de evolução linear, mas usando mesmo assim, de maneira algo redutora o termo - se o teatro de marionetas começa, dizia, por parecer implicar um desaparecimento da pessoa humana do manipulador, em favor dos bonecos que ele manipula, este teatro acaba por passar a incluir, de maneira flagrante ao longo do último século, a figura humana como parte integrante da sua visibilidade. Ela já lá estava, claro, mas hoje ela faz parte do teatro de marionetas e de formas animadas como outro elemento qualquer. Mais ainda, a figura humana, seja ela a do manipulador ou não, é frequentemente redefinida pela prática ou pela inclusão num tipo de teatro em que ela parecia estar oculta. 0 Teatro de Marionetas do Porto, sob a reflexão criativa de João Paulo Cardoso, tem sido exemplar nessa articulação entre elementos não humanos e humanos. Basta recordarmos o espectáculo que há poucas semanas aqui foi apresentado, Nada ou o silêncio de Beckett, para disso termos uma prova concludente. Por outro lado, e em relação ainda com este primeiro aspecto, o teatro de marionetas que João Paulo Seara Cardoso fez é um teatro que alarga o espectro da natureza do acto teatral em si mesmo, por inclusão de dimensões que, sendo reivindicadas por muita da prática, da crítica e da teoria mais ou menos recente, já estavam neste tipo de teatro, sendo explicitadas de forma brilhante e - o que é importante - aparentemente pacífica e natural, pelos mesmos espectáculos atrás referidos, e por muitos outros que não referi. Veja-se, em muitos destes espectáculos,

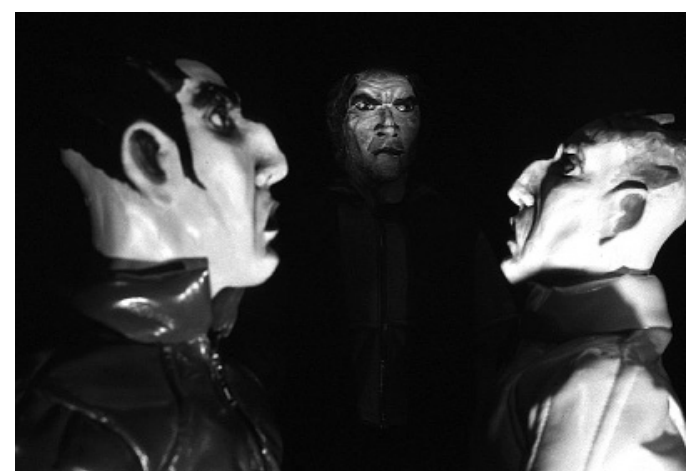

FIMFA Lx10,

Shrimp Tales,

Hotel Modern, Holanda, fot. Leo Van Velzen

Macbeth,

enc. João Paulo Seara

Cardoso,

Teatro de Marionetas

do Porto, 2001,

fot. Susana Neves o que acontece a expressões como "teatro de imagens", "teatro visual", "teatro dramático", "teatro pós-dramático", "conteúdos cognitivos hermenêuticos", "sugestões cognitivas não hermenêuticas". Veja-se o caso da utilização não discriminatória e sempre orgânica da palavra, da música, da coreografia, do som, da luz, das imagens em geral.

Veja-se ainda, a este propósito, a facilidade com que, em vários espectáculos, a construção de um universo de conteúdos complexos e significados difusos aponta para um acto de leitura stricto sensu, sendo o espectáculo, que transborda muito para além do universo dos textos e dos livros, um resultado de uma leitura atenta e empenhada desses mesmos textos e livros.

Finalmente, julgo ser importante referir o facto de este universo exigir por parte dos criadores uma componente de competência técnica incontornável (e o papel pedagógico que o João Paulo Seara Cardoso teve no universo teatral em Portugal foi, aliás, inestimável). É essa ligação entre imaginação, talento e competência técnica que permite uma criação artística efectivamente livre. Por outro lado, tal universo criativo exige tempo, e não se compadece com a sobreposição de criação artística e produção em cadeia. Para criar em liberdade e com seriedade é preciso tempo. Esta dimensão, que as instâncias do poder nas suas diversas modalidades e nos seus diversos graus hoje tendem a rasurar, a ponto de muitos artistas assumirem para si mesmos a lógica do fast food, nunca poderá vir a criar objectos que, dois mil anos depois do seu nascimento, ainda consigam falar às pessoas que, como nós, os vemos e por eles nos encantamos.

\section{Referência bibliográfica}

PLASSARD, Didier (1996), Les mains de lumière: Anthologie des écrits sur I'art de la marionnette, Charleville-Mézières, Institut International de la Marionette. 